\title{
Metodologias Ativas no Ensino Médio: experiência com sala de aula invertida e aprendizagem a pares.
}

\author{
Active Methodologies in High School: flipped \\ classroom experience and peer instruction.
}

ADRIANA MOREIRA DA ROCHA VEIGA

Universidade Federal de Santa Maria

LUÍS MIGUEL DIAS CAETANO

Universidade da Integração Internacional da Lusofonia Afro-Brasileira

MÁRCIA MYCHELLE NOGUEIRA DO NASCIMENTO

Programa de Pós-Graduação em Educação, Universidade Federal de Santa Maria

\begin{abstract}
Resumo: Este artigo tem como objetivo analisar as percepções dos alunos sobre os processos de ensino e aprendizagem com a utilização de metodologias ativas no ensino médio, particularmente, na sala de aula invertida e a aprendizagem a pares. As atividades foram realizadas numa turma de ensino médio na disciplina de História através do uso de dispositivos móveis (tablets e celulares). Como metodologia seguimos uma abordagem qualitativa, recorrendo à técnica de estudo de caso e os dados foram coletados através de micronarrativas produzidas em formato de vídeo pelos alunos participantes. Os resultados apontam para o fato das metodologias ativas aplicadas terem um impacto significativo na aprendizagem ao nível da mudança de comportamentos e atitudes, nos níveis de concentração, nos níveis motivacionais e na maior interatividade. Os resultados apontam ainda como impacto no ensino um maior acompanhamento das aprendizagens e atribuição de novos papéis aos alunos.
\end{abstract}

Palavras-chave: Metodologias ativas. Sala de aula invertida. Aprendizagem a pares. Ensino médio.

\begin{abstract}
This article aims to analyze students perceptions about teaching and learning processes using active methodologies in High School, particularly, the flipped classroom and peer instruction. The activities were carried out in a High School class, in History' subject, through the mobile devices' use (tablets and cell phones). In methodology, we took a qualitative approach, using the case study technique; the data were collected through micronarratives produced on videos by the participating students. The results present that the active methodologies used have a significant impact on learning, in terms of changing behaviors, attitudes, concentration, motivation and greater interactivity ones. The results also point out as an impact on teaching a greater monitoring of learning and assigning new roles to students.
\end{abstract}

Keywords: Active methodologies. Flipped classroom. Peer instruction. High school. 
VEIGA Adriana Moreira da Rocha; et al. Metodologias Ativas no Ensino Médio: experiência com sala de aula invertida e aprendizagem a pares. Informática na Educação: teoria \& prática, Porto Alegre, v. 23, n. 2, p. 177-194, maio./ago. 2020.

\section{Introdução}

As alterações ocorridas na atual sociedade tecnológica têm criado desafios aos ambientes educativos. Entre os inúmeros desafios estão aspetos como o "nível do acesso à informação, na diversidade de meios, nos tipos de aprendizagem, nos tipos de comunicação e no novo perfil de alunos e professores" (CAETANO, 2015, p. 306). Para o autor, escolas, professores e alunos passaram a ter novas formas de se comunicar, onde a tecnologia possibilita novos ambientes virtuais de aprendizagem, permitindo que a escola possa assumir novas formas e novos espaços.

Reconhecendo o professor como o principal agente educativo capaz de operar as mudanças necessárias no contexto atual das escolas, onde as metodologias ativas se apresentam como um desafio, torna-se necessário conhecer o novo perfil dos alunos, as potencialidades dessas metodologias e os procedimentos para a sua implementação.

A tecnologia tem transformado o perfil dos novos alunos. Os alunos deste século, muitas vezes denominados de "nativos digitais" (PRENSKY, 2010), apresentam-se com novos conhecimentos e novos comportamentos nos ambientes educativos: (a) não querem permanecer sentados ouvindo o professor; (b) querem que suas opiniões sejam válidas e respeitadas; (c) querem produzir usando os recursos do seu tempo; (d) querem se conectar com os seus pares para partilhar conhecimento dentro e fora da sala de aula; (e) querem uma educação que faça sentido para o seu cotidiano; (f) querem aprender de forma significativa para que o tempo que passam na escola seja valioso e que acolha o uso das tecnologias que já utilizam fora da sala de aula.

Convém, no entanto, destacar que o conceito de "nativos digitais" merece alguma ponderação na realidade brasileira perante disparidades de natureza socioeconômica em que muitos alunos não têm acesso a determinados meios tecnológicos (BRAGA, 2012). De qualquer modo, apesar dessa limitação, não se deve deixar de vislumbrar um perfil de professor que valorize as experiências e conhecimentos dos alunos e consiga encontrar estratégias para a integração de novas metodologias e das tecnologias nas práticas educativas.

Para além da designação de "nativos digitais" usada por Prensky (2001), outros autores têm atribuído novas designações à geração do século XXI:

- Geração Net (Oblinger \& Oblinger, 2005): jovens que sabem se expressar melhor por imagens e criações multimídias do que por textos e que têm grandes habilidades em sair do mundo real para o virtual;

- Geração Polegar (RHEINGOLD, 2003): termo atribuído para identificar uma geração que, pelas suas capacidades, escrevem mensagens usando apenas os polegares;

- Screenagers (ALVES, 2005): geração que vive na idade das telas interagindo com joysticks, mouse, internet e controle remoto; pensam e aprendem de forma diferenciada;

- Homo Pixelus (KOSTER, 2005): baseado na teoria da diversão para design de jogos. O autor designa a geração como dependente dos pixels que caracterizam a grande variedade de jogos de computador; 
- Homo Zappiens (VEEN; VRAKKING, 2009): atribuição dada à geração que atua e reage de forma dispersa na visão dos professores, mas, na realidade, são multifuncionais e conseguem manipular rapidamente os meios tecnológicos;

- Superficiais (CARR, 2012): termo atribuído a uma geração que está ficando mais dispersa e superficial por culpa da internet. Segundo o autor, temos acesso a inúmeras informações, mas com pouca profundidade, fazendo com que sejamos uma geração "ask Google", ou seja, que tudo perguntamos ao Google.

Uma pesquisa realizada pela Fundação Telefônica Vivo (2016), junto de 1440 jovens brasileiros com idades compreendidas entre 15 a 29 anos, revelou que (a) o celular é o principal dispositivo para acessar à internet (85\%), (b) $49 \%$ dos jovens afirmou acessar à internet mais de uma vez por semana; (c) $99 \%$ dos jovens entrevistados, afirmou usar regularmente aplicativos de conversa, em especial, o WhatsApp, (c) $41 \%$ dos jovens entrevistados, afirmou jamais utilizar a internet para realizar estudos e trabalhos para a escola, (d) as atividades de lazer menos praticadas são a leitura de "livros digitais" e "acessar a sites de revistas".

Com estes dados verificamos que o perfil dos jovens lança desafios para o mundo da educação. Para Kenski (2015, p. 91) "estamos vivenciando um momento de transição social que se reflete em mudanças significativas na forma de pensar e fazer educação". A autora acrescenta ainda que "os paradigmas da educação tradicional, baseados na educação compulsória e massiva para todos os estudantes, já não satisfazem" (2015, p. 92).

As metodologias ativas, nomeadamente, a sala de aula invertida (flipped classroom) e a aprendizagem a pares (peer instruction), quando combinadas com recursos tecnológicos, potenciam de forma mais célere a inovação educacional e a melhoria das aprendizagens. Nesse sentido, torna-se necessário o aprofundamento destas metodologias e dos procedimentos para a sua implementação, nomeadamente, através do domínio das tecnologias digitais.

A relevância das metodologias ativas para o sistema de ensino brasileiro é de extrema importância dado os resultados da pesquisa "Juventude Conectada" realizada no Brasil (VIVO, 2016), que aponta para "a necessidade de se renovar o modelo de ensino atualmente em vigor". A mesma pesquisa destaca ainda que duas das principais críticas ao modelo atual de ensino estão no fato da relutância em integrar as tecnologias e as regras que vedam a autonomia dos alunos, tais como: (a) o modelo pedagógico centrado na sala de aula; (b) o papel do professor é visto como o único que detém e transmite conhecimento;(c) a organização das disciplinas muito segmentada; (d) a escola tem políticas pouco receptivas quanto ao uso do celular, outros equipamentos e aplicativos.

Nessa linha de pensamento, cabe às escolas assumirem a liderança de ações que permitam se aproximar ao novo perfil dos jovens. Além disso, encontramos referências que anunciam metodologias ativas (Mazur, 2015; Rodrigues, 2016; Moran, 2018), que permitem integrar a tecnologia no ensino, tais como, ensino híbrido, flipped classroom, peer instruction, mobile learning, entre outros.

Nesse sentido, o artigo tem como objetivo analisar as percepções dos alunos sobre os processos de ensino e aprendizagem com utilização de metodologias ativas no ensino médio, 
particularmente, na sala de aula invertida e a aprendizagem a pares. Para a realização da pesquisa foram realizadas atividades com uso de metodologias ativas numa turma de ensino médio na disciplina de História na rede pública de educação do Estado do Rio Grande do Norte. A escolha pela disciplina de História deveu-se ao fato de um dos autores ser docente da área e de estar desenvolvendo um projeto sobre mobile learning e metodologias ativas nas aulas da referida disciplina.

A escolha pelas metodologias ativas encontra-se em sintonia com outras pesquisas realizadas na disciplina de História (SANTOS e TEZANI, 2018; RODRIGUES, 2019), em que foram encontrados resultados positivos ao nível do trabalho colaborativo, aprendizagem ativa, motivação e autonomia dos alunos.

O artigo apresenta, num primeiro momento, o conceito de metodologias ativas a partir do referencial teórico e os contributos de Moran (2015, 2018), Eison (2010) e Prince (2004). Num segundo momento, apresentamos os conceitos e o potencial da sala de aula invertida (BERGMANN e SAMS, 2018) e da aprendizagem a pares (MAZUR, 2015; LIMA e SANTOS, 2016).

Após a caraterização dos procedimentos metodológicos (métodos, técnicas, amostra e instrumentos de coleta de dados), procedemos a uma sistematização dos resultados encontrados.

\section{Metodologias Ativas}

Para Moran (2018, p. 4) as "metodologias ativas são estratégias de ensino centradas na participação efetiva dos estudantes na construção do processo de aprendizagem, de forma flexível, interligada e híbrida". Ainda para o autor, a combinação de metodologias ativas com tecnologias digitais permite que se aprenda melhor através da junção de práticas, atividades, jogos, problemas e projetos relevantes que sejam desenvolvidos de modo colaborativo e personalizado (MORAN, 2015).

Essas metodologias ativas, segundo um conjunto de autores (EISON, 2010; FELDER; BRENT, 2009; PRINCE, 2004), se caracterizam por promoverem uma participação ativa dos alunos nos processos de aprendizagem. Para Bonwell e Eison (1991) essa participação, consiste no envolvimento dos alunos em fazerem as coisas e pensarem sobre o que estão fazendo.

Para conseguir envolver os alunos nesse processo de aprendizagem ativa são propostas algumas estratégias: pensar criticamente ou criativamente; debater com um colega, com um pequeno grupo ou com a turma toda; expressar ideias através da escrita; explorar atitudes e valores pessoais; dar e receber feedback e refletir sobre o processo de aprendizagem (EISON, 2010).

Todas estas estratégias possibilitam a construção de um conhecimento mais significativo, caraterizado pelo envolvimento dos alunos. As estratégias propostas rompem com o ensino tradicional onde assistimos à mera apresentação de conteúdos pelo professor e o aluno assiste passivamente. Neste caso, "as metodologias ativas dão ênfase ao papel protagonista do aluno, 
ao seu envolvimento direto, participativo e reflexivo em todas as etapas do processo, experimentando, desenhando, criando, com orientação do professor" (MORAN, 2018, p. 4).

Na mesma linha de pensamento, Prince (2004) caracteriza que os elementos centrais da aprendizagem ativa são as atividades do aluno e o seu envolvimento no processo de aprendizagem. Para o autor, essas atividades devem ser projetadas em torno dos resultados de aprendizagem, na promoção do envolvimento cuidadoso por parte do aluno e, nesses casos, os ganhos de aprendizagem serão maiores com o seu engajamento do que com o tempo gasto nos conteúdos. Desse modo, a aprendizagem ativa pode acontecer mesmo numa situação, aparentemente caracterizada por ensino tradicional, em que o professor discorre sobre os conteúdos e, em alguns momentos, faz pausas para inserir atividades que promovam a interação dos alunos.

Segundo Moran (2018, p. 12),

A combinação de metodologias ativas com tecnologias digitais móveis é hoje estratégica para a inovação pedagógica. As tecnologias ampliam as possibilidades de pesquisa, autoria, comunicação e compartilhamento em rede, publicação, multiplicação de espaços e tempos.

Assim, as metodologias ativas aliadas às tecnologias digitais podem trazer grandes contributos para o processo de ensino e aprendizagem, nomeadamente, por convidar professores e alunos a novos papéis e na aproximação dos contextos escolares às realidades e perfis dos alunos. Entre essas metodologias, encontramos a sala de aula invertida e aprendizagem a pares que, entre outros aspetos, promovem aprendizagens mais dinâmicas (SANTOS; TEZANI, 2018) e incrementam motivação nos processos de aprendizagem (RODRIGUES, 2019).

\subsection{Sala de Aula Invertida}

A sala de aula invertida, também designada como "Flipped Classroom" surgiu da iniciativa de dois professores norte-americanos, Jonathan Bergmann e Aaron Sams, da área de Química. Os professores lecionavam num contexto rural e eram confrontados com a falta de assiduidade de um grande número de alunos por participação em atividades desportivas e dificuldades de transporte. Os alunos que faltavam tinham grandes dificuldades em recuperar os conteúdos perdidos. Certo dia, Aaron Sams apresentou a Jonathan Bergmann um artigo científico que abordava um software que permitia a gravação dos slides em formato de vídeo e áudio.

Nesse momento, começaram a gravar e a publicar on-line uma grande quantidade de vídeos referentes às suas aulas de Química que, em pouco tempo, despertaram o interesse de muitos alunos e professores dos EUA e do mundo. Nascia assim, o conceito de sala de aula invertida como metodologia que coloca o aluno em contato com os conteúdos fora da sala de aula e converge para a sala de aula (presencial) a realização de debates, reflexões, esclarecimentos de dúvidas e elaboração de projetos.

Para Bergmann e Sams (2018, p. 11), o conceito de sala de aula invertida consiste "no que tradicionalmente é feito em sala de aula, agora é executado em casa, e o que tradicionalmente 
é feito como trabalho de casa, agora é realizado em sala de aula". É a inversão do local de realização das tarefas que dá origem ao termo "sala de aula invertida".

Quando questionados sobre a metodologia da "sala de aula invertida", principalmente, no que concerne aos procedimentos (rotinas), os autores apresentam algumas das suas experiências: começar a aula com uns minutos de discussão sobre um vídeo assistido em casa; preparar os alunos para assistir o vídeo de forma eficaz (desligando aplicativos dos celulares que podem desviar a atenção, pausar e retroceder os vídeos para fazer anotações importantes); incentivar os alunos a registrar as dúvidas e resumir o conteúdo aprendido; avaliar a qualidade dos vídeos em função das perguntas e incompreensões dos alunos; começar a aula dando respostas e esclarecimentos aos alunos; passar as tarefas para execução em sala; experiências em laboratório, pesquisas, solução de problemas ou testes.

A metodologia da sala de aula invertida oferece grande contribuição para a aprendizagem dos alunos. Falamos do fato dos alunos terem contato com os conteúdos em casa. Nesse momento, é confrontado com eventuais dificuldades que o direcionam para uma revisão dos conteúdos e para o registro das suas dúvidas afim de serem esclarecidas em sala de aula presencial. Esta situação difere do ensino tradicional porque os alunos passam horas em sala de aula ouvindo passivamente os professores e, em muitos casos, se confrontando com dúvidas, permanecendo sem esclarecê-las.

Umas das questões igualmente importante, é a capacidade dos professores conseguirem avaliar a qualidade e a aprendizagem realizada em casa. Na tentativa de propor algumas soluções, Bergmann (2018) elenca algumas ferramentas tecnológicas digitais para fomentar a responsabilização, interatividade e feedback. Essas ferramentas on-line permitem coletar informações durante e após a visualização dos vídeos.

O autor sugere o recurso do Formulário Google, EDpuzzle, Microsoft Office Mix e PlayPosit. Por exemplo, o Formulário Google possibilita ao professor criar quizzes aos quais os alunos respondem, gerando um relatório de resultados. O EDpuzzle permite a edição de um vídeo e, no decorrer da sua exibição, introduzir comentários e questões, realizando pausas para que o aluno possa responder às perguntas enquanto assiste.

A sala de aula invertida tem merecido uma crescente atenção pelos resultados positivos que tem trazido ao ensino e aprendizagem. São conhecidas inúmeras vantagens: na redução da evasão escolar, desempenho dos alunos, redução da repetência em disciplinas e a criação de momentos inovadores (RODRIGUES, 2016; VALENTE, 2014).

Logo, o fato dos alunos levarem, cada vez mais, celulares e outros dispositivos móveis para as escolas permitiu que eles, em alguns contextos, passassem a ser integrados em sala de aula, numa situação que, muitas vezes, as escolas não possuem recursos tecnológicos. Esse conceito designado de BYOD - Bring Your Own Device, segundo Carvalho (2015), tem promovido o aumento de experiências com sala de aula invertida.

\subsection{Aprendizagem a Pares}


A metodologia Peer Instruction (aprendizagem a pares), surgiu nos primeiros anos da década de 1990 por um professor de física holandês, Eric Mazur. A metodologia consiste num ensino por pares e teve origem pelo fato dos alunos terem dificuldades em compreender assuntos de física e matemática (MAZUR, 2015).

A aprendizagem a pares propõe a aprendizagem de conceitos essenciais e, com isso, leva os estudantes a obterem melhores resultados na resolução de problemas. Segundo Mazur (2015, p. 10), para que a aprendizagem a pares seja bem-sucedida "é necessário que o livro e as aulas expositivas desempenhem papéis diferentes dos que costumam exercer em uma disciplina convencional". O autor acrescenta ainda que as atividades de leitura dos conteúdos das aulas devem acontecer com antecedência. Em seguida, nas aulas expositivas se esclarecem as dúvidas e apresentam exemplos para aprofundar a compreensão. Desse modo, os livros didáticos têm apenas um papel de referência e guia de estudo.

Os objetivos básicos da aprendizagem a pares são: (a) explorar a interação entre os estudantes durante as aulas expositivas; (b) levar os estudantes a se concentrarem nos conceitos fundamentais; (c) garantir que as aulas sejam pautadas por apresentações curtas sobre pontos chave; (d) elaborar testes conceituais para verificar as aprendizagens realizadas; (e) facultar um tempo para que os estudantes possam responder e depois debater entre si às questões propostas (MAZUR, 2015).

Estes processos oportunizam que os estudantes se esforcem a pensar com base nos argumentos que estão sendo desenvolvidos e dar-lhes uma oportunidade para avaliar a sua compreensão sobre os conceitos.

São conhecidos vários resultados da aprendizagem a pares como as discussões para convencer os colegas e, que quebrem as aulas expositivas; os estudantes não se limitarem apenas ao conhecimento disponível nos materiais, mas, principalmente, na verbalização e reflexão. Outra vantagem está no fato dos testes conceituais fornecerem um feedback imediato sobre o nível de aprendizagem (MAZUR, 2015).

De acordo com Lima e Santos (2016, p. 1), a aprendizagem a pares "é uma das mais importantes metodologias ativas de ensino-aprendizagem para estimular estudantes e obter feedback em tempo real com grande precisão acerca do aprendizado sobre um determinado tópico exposto durante uma aula". Os autores realizaram experiências, no ensino médio, recorrendo aos grupos de trabalho criados no Facebook e WhatsApp com o objetivo de serem um espaço de discussão sobre os temas de Física e como forma de avaliar os progressos dos alunos recorreram à plataforma Google Forms.

O recurso a meios tecnológicos na metodologia aprendizagem a pares é também uma das iniciativas seguidas por Leite (2018) usando Flashcards (on-line), Survey Monkey e Google Forms.

Em suma, a aprendizagem a pares consiste em tirar o foco da aula tradicional (transferência de informações) e estimular a busca pelo conhecimento de forma autônoma. Esse processo é apoiado em leituras antes das aulas (ligadas aos temas propostos), o professor fomenta e medeia o debate entre os alunos e lança questões conceituais baseadas nas dificuldades da turma. Desse 
modo, as aulas se tornam mais participativas e proporcionam mais interatividade entre os alunos e professores no processo de aprendizagem.

\section{Metodologia}

A metodologia utilizada para a pesquisa realizada baseou-se numa abordagem qualitativa (OLIVEIRA, 2016) com recurso à técnica de estudo de caso (YIN, 2001) e os dados coletados através de micronarrativas dos alunos (SAHAGOFF, 2015).

Já no sentido de analisar as percepções dos alunos sobre os processos de ensino e aprendizagem relacionados à utilização de metodologias ativas recorremos ao uso de micronarrativas produzidas pelos alunos ao longo de dez sessões, com duração de 50 minutos cada (1h/aula), realizadas na disciplina de História.

Essa escolha deveu-se ao fato de desejarmos obter relatos das experiências dos alunos face à utilização das metodologias ativas (sala de aula invertida e aprendizagem a pares) mediadas por dispositivos móveis (tablets e celulares), alinhados desse modo à indicação de Sahagoff (2015, p. 2), nos aponta que a "experiência é um fator importante para a pesquisa narrativa". Além disso, outras pesquisas similares coletaram dados através de questionários (RODRIGUES, 2019) e entrevistas (SANTOS; TEZANI, 2018). Consideramos que as micronarrativas acrescentaram outros detalhes aos relatos das experiências vivenciados pelos alunos.

A utilização de narrativas tem sido frequente em várias áreas do conhecimento como a Sociologia (SANTOS; VOLTER; WELLER, 2014), a Linguística (VIEIRA; FERRONATO, 2017) e a Pedagogia (SAHAGOFF, 2015). Para Gibbs (2009), as narrativas consistem na narração de histórias que dão sentido as experiências passadas, permitem compreender o sentido dos eventos e têm como fonte as entrevistas ou algum estímulo que promova o relato de experiências. No nosso caso, considerando o pedido de produção de narrativas de curta duração, optamos por designá-las de micronarrativas conforme o termo que também é utilizado por outros autores (VIEIRA; FERRONATO, 2017) para se referirem a pequenos relatos.

A pesquisa teve como amostra uma turma de Ensino Médio composta por 25 alunos, com idade média de 16 anos, maioritariamente do gênero masculino $(n=14 ; 56 \%)$ e residentes $(n=19 ; 76 \%)$ no meio rural.

Foram dinamizadas cinco sessões com atividades orientadas de acordo com a metodologia sala de aula invertida e cinco sessões orientadas para a metodologia aprendizagem a pares com uso de dispositivos móveis (tablets e celulares) e apps, seguindo as orientações de Bergman e Sams (2018) e Mazur (2015) para promover a participação dos alunos na construção do processo de aprendizagem e criar a oportunidade de terem contato com os conteúdos da disciplina de História fora da sala de aula (sala de aula invertida) e de interação entre os alunos (aprendizagem a pares).

Em termos globais, as sessões tinham como objetivo principal compreender o processo de emancipação política da Colônia Portuguesa na América, identificando os grupos sociais 
envolvidos nesse período histórico. Durante as sessões de sala de aula invertida foram explorados os temas relacionados à caracterização do processo de emancipação política e nas sessões dinamizadas pela metodologia aprendizagem a pares foram trabalhos temas relacionadas às consequências desse processo.

Para isso, foi orientado o estudo fora da sala de aula, atividades além do horário das sessões, com textos e vídeos e, produção de registros de dúvidas e incompreensões, em destaque pontos relevantes para serem discutidos em sala.

$\mathrm{Na}$ organização das sessões com uso da metodologia da sala de aula invertida, demos destaque à realização de atividades que permitissem a utilização de dispositivos móveis (tablets e celulares) e o app Kahoot, seguindo as orientações de Bergman e Sams (2018) para promover a participação dos alunos na construção do processo de aprendizagem e criar a oportunidade de terem contato com os conteúdos fora da sala de aula. As sessões na escola foram realizadas no laboratório de informática com os alunos dispostos em filas e agrupados em dupla (dois alunos por cada tablet). Foi realizado um planejamento das sessões, atribuindo papéis aos alunos e ao professor e, na ocasião, foi definido: ações iniciais, orientação para o acesso aos recursos fora da sala, atividades para a promoção da reflexão sobre as descobertas, formas de interação com os dispositivos móveis e o app Kahoot, modo de resolução de questões, processo de análise dos erros (recurso a projeções e interação com $a p p$ ) e orientações para produção textual reflexiva.

No caso das sessões para uso da metodologia aprendizagem a pares, foi utilizado o mesmo tipo de planejamento, no entanto, tivemos como preocupação estimular a busca pelo conhecimento de forma autônoma, possibilitar que os alunos tivessem contato com os conteúdos fora da sala de aula e explorar a interação entre os alunos, organizados em dupla durante as aulas. A partir disso, planejamos as atividades com utilização de tablets e do app Nearpod, principalmente vocacionadas para a aprendizagem a pares e reunindo os princípios propostos por Mazur (2015): debates online, apresentações em grupo, discussão e negociação de decisões. Os debates online foram realizados como atividades de casa e registrados de forma assíncrona num grupo fechado no Facebook. Durante as sessões, os grupos foram constituídos pelos próprios alunos e, nos casos em que as discussões originavas divergências, os grupos dialogavam entre si e, se necessário, o professor assumia o papel de mediador para auxiliar o grupo na tomada de decisão.

A avaliação formativa durante as sessões foi realizada por meio da participação e interação dos alunos com os apps Kahoot e Nearpod, permitindo que as aprendizagens pudessem ser monitoradas, sendo possível dar um feedback imediato e, ao mesmo tempo, mediar de forma efetiva a aprendizagem. Como elemento adicional, no final das sessões, foi solicitada a produção das micronarrativas (vídeos) no sentido de os alunos realizarem uma reflexão crítica das sessões quanto ao processo de ensino e aprendizagem. O pedido de colaboração aos vinte e cinco alunos para gravação de micronarrativas em formato de vídeo (duração entre 2 a 3 minutos) produzido com os celulares pessoais, após finalização de todas as sessões, deu origem a dezesseis produções individuais (micronarrativas), sendo que, nove alunos não produziram as respectivas micronarrativas. 
Os vídeos das micronarrativas foram inseridos no software de apoio à análise qualitativa disponível em webQDA (www.webqda.net) tendo em vista proceder a análise de conteúdo com recurso de um conjunto de categorias.

Nesse sentido, seguimos as orientações metodológicas de Bardin (2008), selecionamos unidades de análise nas várias fontes de dados (micronarrativas) e construímos categorias de análise recorrendo ao critério semântico (organização por temáticas), sintático (organização por verbos e adjetivos) e léxico (organização pelo sentido das palavras). Construímos ainda algumas categorias pela classificação proposta por Oliveira (2016): categorias teóricas (baseadas em referencial teórico) e empíricas (baseadas nos dados coletados).

Construímos essa análise de conteúdo seguindo as três fases propostas por Minayo (2002): pré-análise (organização e exploração dos materiais através de leitura flutuante), exploração do material (codificação, classificação e categorização) e tratamento dos resultados (tratamentos dos dados brutos dando destaque às informações obtidas). Durante essas três fases, recorremos ao software de análise qualitativa de dados webQDA (Figura 1), dados coletados em registro na forma de vídeo.

Figura 1 - Análise de micronarrativas em vídeo
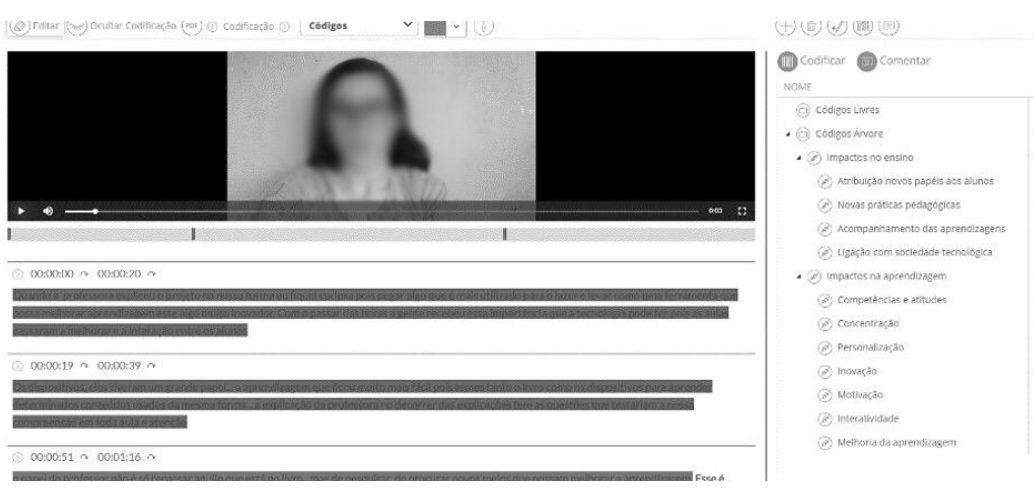

Fonte: Os autores.

A técnica de análise utilizada para avaliar as micronarrativas foi a análise de conteúdo, sendo apoiada pelas seguintes categorias de análise (Figura 2) com as respetivas frequências identificadas no webQDA como referências (REFS):

a) Quanto à aprendizagem: motivação, personalização, inovação, competências e atitudes, concentração, interatividade, melhoria da aprendizagem;

b) Quanto ao ensino: atribuição novos papéis aos alunos, acompanhamento das aprendizagens, ligação com sociedade tecnológica e novas práticas pedagógicas). 


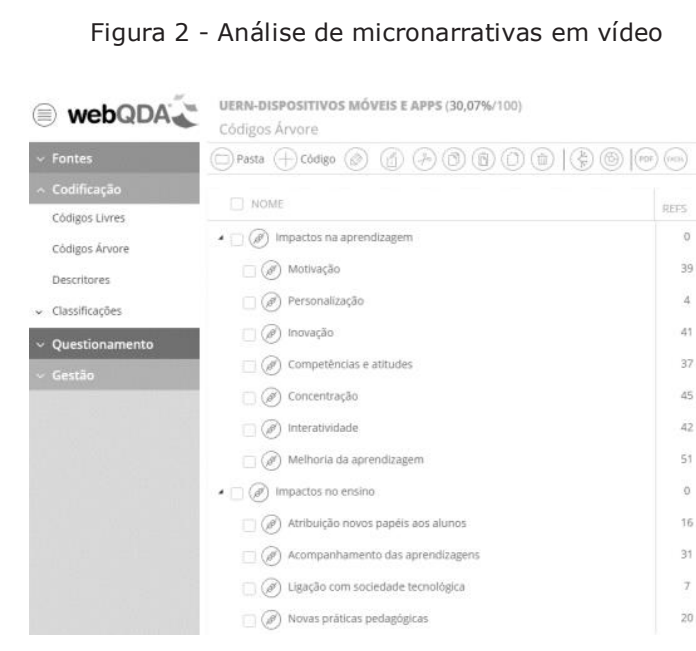

Fonte: Os autores.

Para análise e sistematização dos resultados, foram elaboradas quatro matrizes na área de questionamento do software webQDA: (1) sala de aula invertida - aprendizagem; (2) sala de aula invertida - ensino; (3) Aprendizagem a pares - aprendizagem; (4) Aprendizagem a pares ensino.

Figura 3 - Matrizes para análise de dados

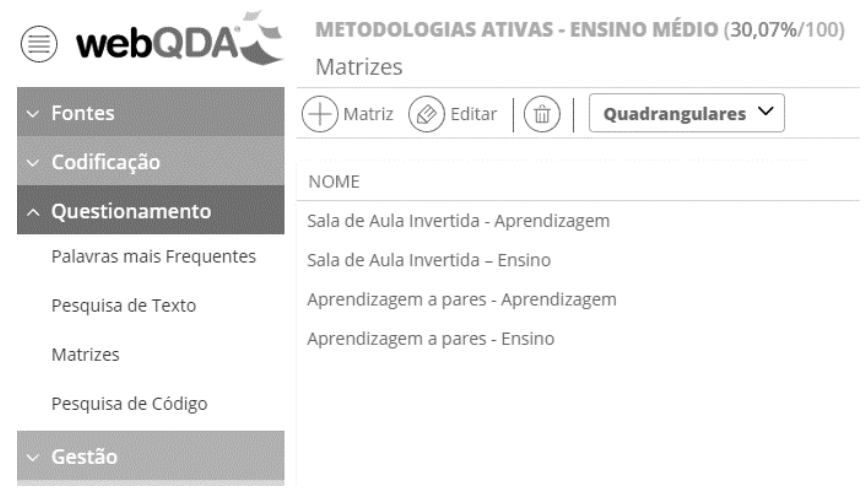

Fonte: Os autores.

Com isso, a utilização de softwares do tipo QDAs (Qualitative Data Analysis) releva-se de suma importância em pesquisas de abordagem qualitativa, nas quais surgem vários tipos de fontes (texto, vídeo, áudio e imagem) e com os respetivos softwares permitem elaborar análises através de sistemas de codificação, facilitando assim a interpretação dos resultados (CAETANO, 2017). 


\section{Resultados}

Os resultados da análise de conteúdo foram realizados através de tabelas com apresentação da frequência absoluta ( $n$ ) e relativa (\%) referentes ao número de unidades de análise identificadas nas micronarrativas e que foram enquadradas nas respetivas categorias de análise.

Em resultado das cinco sessões dinamizadas com a metodologia da sala de aula invertida, foram encontrados resultados que revelam as principais percepções ao nível da aprendizagem: mudança em comportamentos e atitudes $(28,1 \%)$, a melhoria da aprendizagem $(21,1 \%)$ e a interatividade $(17,5 \%)$.

Tabela 1 - Sala de Aula Invertida: percepções ao nível da aprendizagem

\begin{tabular}{|c|c|c|}
\hline Percepções na aprendizagem & $\mathbf{n}$ & $\mathbf{\%}$ \\
\hline Motivação & 7 & $12,3 \%$ \\
\hline Inovação & 8 & $14,0 \%$ \\
\hline Competências e atitudes & 16 & $28,1 \%$ \\
\hline Concentração & 4 & $7,0 \%$ \\
\hline Interatividade & 10 & $17,5 \%$ \\
\hline Melhoria da aprendizagem & 12 & $21,1 \%$ \\
\hline Total de referências & 57 & $100 \%$ \\
\hline
\end{tabular}

Fonte: Os autores.

Como exemplo das referências encontradas nas micronarrativas relacionadas aos impactos de nível da aprendizagem verificados na metodologia da sala de aula invertida, apresentamos algumas unidades de análise referentes às três categorias que tiveram maior frequência:

Quanto a "Competências e atitudes":

"faz com que todos os alunos participem e todos possam compartilhar o que aprendeu (aluno 14);

uma forma diferente de nos fazer participar e aprender (aluno 16);

a gente participa também orientando e repassando o que aprendemos e o que adquirimos em cada assunto" (aluno 23).

Quanto a "Melhoria da aprendizagem":

"a utilização dos tablets e de alguns aplicativos ajudam bastante para aprender" (aluno 3);

"melhorando nossa aprendizagem com mais recurso dando uma grande oportunidade de conhecimento" (aluno 12);

"melhores aulas com os tablets aprendi muito mais" (aluno 14).

Quanto a "Interatividade":

"há muita interação de todos" (aluno 5);

"muito interativo tornando o modo de aprender mais prazeroso e fácil" (aluno 6);

"A utilização do kahoot e dos tablets é uma maneira inovadora que faz com que nós tenhamos mais interação" (aluno 8). 
Nas sessões orientadas para a sala de aula invertida, os alunos destacaram como principal categoria a mudança de "Competências e atitudes" revelando, por exemplo, que eram membros ativos no processo de aprendizagem.

Por outro lado, mereceu ainda o destaque a categoria da "Interatividade" tendo como evidência um novo processo de dinamização da aprendizagem conseguida pela interação proporcionada pelos aplicativos e dispositivos móveis.

Ao nível das percepções no ensino, identificamos no resultado das sessões com orientação para a sala de aula invertida que o principal destaque foi a atribuição de novos papéis aos alunos $(57,1 \%)$ e acompanhamento das aprendizagens $(42,9 \%)$.

Tabela 2 - Sala de Aula Invertida: percepções ao nível do ensino

\begin{tabular}{|c|c|c|}
\hline Percepções no ensino & $\mathbf{n}$ & $\mathbf{\%}$ \\
\hline Atribuição novos papéis aos alunos & 4 & $51,7 \%$ \\
\hline Acompanhamento das aprendizagens & 3 & $42,9 \%$ \\
\hline Total de referências & 7 & $100 \%$ \\
\hline
\end{tabular}

Fonte: Os autores

À semelhança dos resultados ao nível da aprendizagem, os alunos também reconheceram que a metodologia utilizada nas sessões promoveu novos papéis:

"achei uma bela forma de puxar o aluno pra uma discussão" (aluno 7);

"uma forma diferente e muito boa, pois, faz com que estude e mostre nossos conhecimentos para os colegas e eles compartilhar os deles" (aluno 8);

"além do professor estar presente para nos orientar, a gente participa também orientando e repassando o que aprendemos" (aluno 23).

Os alunos conheceram ainda o fato do professor ter a oportunidade de acompanhar as suas aprendizagens através das funcionalidades disponíveis nos aplicativos utilizados:

"dá pra avaliar cada aluno pra saber se ele estuda ou não" (aluno 6);

"o kahoot é uma ótima sacada pra avaliar e repassar conhecimento" (aluno 9);

"dará sinais ao professor de quem realmente estudou e de quem não se preparou" (aluno 23).

Os resultados ao nível das percepções no ensino revelaram o reconhecimento dos alunos pela importância de lhes atribuírem novos papéis, permitindo que o seu conhecimento fosse valorizado e partilhado com os colegas. Além disso, os alunos perceberam que através das metodologias utilizadas, as suas aprendizagens foram acompanhadas, possibilitando registros de aprendizagens, erros e dificuldades.

Em seguida, destacamos os resultados relativos às atividades organizadas no âmbito da metodologia aprendizagem a pares.

Da análise de conteúdo realizada às micronarrativas, encontramos, ao nível da aprendizagem como subcategorias que mais acolheram registros de unidades de análise: concentração $(36,4 \%)$, interatividade $(18,2 \%)$ e competências e atitudes $(16,7 \%)$.

Tabela 3 - Aprendizagem a Pares: percepções ao nível da aprendizagem

\begin{tabular}{|c|c|c|}
\hline Percepções na aprendizagem & $\mathbf{n}$ & $\mathbf{\%}$ \\
\hline Motivação & 7 & $10,6 \%$ \\
\hline Personalização & 1 & $1,5 \%$ \\
\hline Inovação & 4 & $6,1 \%$ \\
\hline Competências e atitudes & 11 & $16,7 \%$ \\
\hline Concentração & 24 & $36,4 \%$ \\
\hline Interatividade & 12 & $18,2 \%$ \\
\hline Melhoria da aprendizagem & 7 & $10,6 \%$ \\
\hline
\end{tabular}




\begin{tabular}{|c|c|c|}
\hline Total de referências & 66 & $100 \%$ \\
\hline
\end{tabular}

Fonte: Os autores.

Para Mazur (2015), autor considerado como pioneiro da metodologia da aprendizagem a pares, essa metodologia leva os estudantes a se concentrarem mais nos conteúdos fundamentais. Na sequência desse dado, verificamos que os resultados apontaram para um reconhecimento dos alunos quanto à sua maior concentração $(n=24 ; 36,4 \%)$ durante as atividades realizadas em sala de aula:

"concentração que acabamos tendo frente a uma apresentação com perguntas faz com que o processo de aprendizagem seja mais rápido então o Nearpod consegue fazer essa fixação" (aluno 1);

"com o nearpod tem as questões fazendo com que todos querem acertar e com isso focam mais no conteúdo" (aluno 3);

"essa tecnologia prende a atenção dos ouvintes" (aluno 6).

Quanto à "Interatividade", outra das funções da aprendizagem a pares reconhecida por Mazur (2015), mereceu o seguinte destaque dos alunos:

"o Nearpod é muito diferente dos slides, nos slides não podemos interagir como interagimos no Nearpod" (aluno 1);

"o Nearpod pode trazer esses benefícios, além de ser fácil de usar e a interação torna-se mútua" (aluno 6);

"há uma grande interação entre os alunos" (aluno 23).

À semelhança da metodologia anterior, a promoção de "novas competências e atitudes" foi uma das subcategorias com maior frequência de unidades de análise:

"houve mais desenvoltura e liberdade" (aluno 1);

"A apresentação com o app faz com que vc se dedique para repassar o máximo de conteúdo" (aluno 5)

"com o Nearpod a gente não tem vergonha de falar" (aluno 7).

$\mathrm{Na}$ percepção dos alunos, as sessões orientadas para a realização de atividades por aprendizagens a pares fomentaram, de modo especial, a melhoria pela concentração e interatividade, permitindo que estivessem mais focados e envolvidos nas tarefas. Estes resultados estão alinhados com o pensamento de Mazur (2015) quando se refere a aprendizagem a pares e permite uma maior interação entre os estudantes durante as aulas expositivas.

Quanto às percepções dos alunos ao nível do processo de ensino nas sessões de aprendizagem a pares, verificamos que deram particular destaque para o "acompanhamento das aprendizagens" (61,5\%) e a "atribuição de novos papéis aos alunos" (38,5\%) (Tabela 4).

Tabela 4 - Aprendizagem a Pares: percepções ao nível do ensino

\begin{tabular}{|c|c|c|}
\hline Percepções no ensino & $\mathbf{n}$ & $\mathbf{\%}$ \\
\hline Atribuição novos papéis aos alunos & 5 & $38,5 \%$ \\
\hline Acompanhamento das aprendizagens & 8 & $61,5 \%$ \\
\hline Ligação com sociedade tecnológica & 0 & $0,0 \%$ \\
\hline Novas práticas pedagógicas & 0 & $0,0 \%$ \\
\hline Total de referências & 13 & $100 \%$ \\
\hline
\end{tabular}

Fonte: Os autores. 
Do mesmo modo que aconteceu ao nível das percepções no ensino, perante a metodologia da sala de aula invertida, no caso da aprendizagem a pares, as subcategorias tiveram maior frequência em o acompanhamento das aprendizagens $(n=8 ; 61,5 \%)$ e os novos papéis atribuídos aos alunos $(n=5 ; 38,5 \%)$. No caso do acompanhamento das aprendizagens, a título de exemplo, apresentamos as seguintes unidades de análise:

"essas questões servem para ver se os alunos prestaram atenção" (aluno 3);

"app também dá a oportunidade da professora saber se os alunos estão entendendo" (aluno 7);

"vai testando o conhecimento e fazendo uma forma de avaliação de cada aluno através do conteúdo e do app" (aluno 11).

Quanto à atribuição de novos papéis, os alunos reconheceram que:

"a diferença é que a gente teve que elaborar o nosso próprio questionamento para avaliar os colegas" (aluno 2);

"a apresentação com o App faz com que você se dedique para repassar o máximo de conteúdo" (aluno 5);

"a partir do aplicativo nasce uma preocupação maior não só de explicar, mas também de fazer com que quem está assistindo entenda" (aluno 6).

Da interpretação das micronarrativas relativas às sessões dinamizadas por uma abordagem à metodologia da aprendizagem a pares, consideramos, portanto, que os alunos revelaram a importância dos apps e dispositivos móveis na promoção da concentração e da interatividade nos processos de aprendizagem. Quanto aos processos de ensino, na opinião dos alunos, o destaque foi para a oportunidade de acompanharem as aprendizagens obtidas durante as sessões e os resultados conseguidos pela promoção de novos papéis aos alunos são diferentes da tradicional aula expositiva onde assumem um papel de passivos.

\section{Conclusões}

A pesquisa possibilitou um maior conhecimento sobre as metodologias ativas, nomeadamente, sobre o seu desenvolvimento, as potencialidades pedagógicas e os impactos que proporcionam aos processos de ensino e aprendizagem.

A experiência de uso da metodologia da sala de aula invertida, mostrou a importância de desenvolver atividades com intencionalidade educativa orientadas para a atribuição de novos papéis aos alunos, permitindo aprendizagens ativas e significativas. A realização das sessões apontou para o fato da metodologia da sala de aula invertida ter como principais impactos, na percepção dos alunos, incrementos da inovação educativa, promoção de novas competências e atitudes nos alunos e maior interatividade nas atividades e, desse modo, uma melhoria nos processos de aprendizagem.

Por outro lado, de acordo com os resultados da nossa pesquisa, a metodologia ao nível dos processos de ensino, revelou que estes passaram a atribuir novos papéis aos alunos e permitiram acompanhar as suas aprendizagens conforme resultados encontrados por Santos e Tezani (2018). 
No que se refere, aos resultados ao nível das sessões com abordagem da metodologia de aprendizagem a pares, verificou-se que os alunos apontaram como principais impactos a melhoria nos níveis de concentração, interatividades no momento de realização das atividades e desenvolvimento de novas competências e atitudes. À semelhança dos resultados anteriores ao nível do ensino, a metodologia de aprendizagem a pares também se apontou como promotora de novos papéis para os alunos e criou oportunidades para acompanhar as suas aprendizagens.

A dinamização das sessões através das metodologias ativas (sala de aula invertida e aprendizagem a pares) contribuíram para promover momentos de melhores de aprendizagens para os alunos em que adquiriram novas competências, estando mais concentrados e motivados à semelhança de pesquisas realizadas por Rodrigues (2019) no âmbito da disciplina de História. Além disso, realizavam tarefas de forma mais interativa, tendo retorno e acompanhamento das suas aprendizagens. Para esses resultados, contribuiu o planejamento rigoroso, a mudança de papéis dos alunos e a utilização de dispositivos móveis e apps.

Os dados analisados apontaram para importantes potencialidades pedagógicas das metodologias ativas como a gestão motivacional, a inovação educativa e o sucesso educativo.

Avaliamos que perante o estudo de caso que foi realizado, os resultados evidenciaram a importância de desenvolver momentos educativos que fomentaram aprendizagens ativas através de processos que levaram os alunos a pensar criticamente, a participarem de debates, a expressarem suas ideias, a explorarem valores pessoais, a terem feedback das suas aprendizagens e a refletirem sobre o seu papel enquanto alunos.

As metodologias ativas usadas nessa pesquisa possibilitaram a construção de um conhecimento mais significativo e com a interação dos alunos. A sala de aula invertida e a aprendizagem a pares rompem com o ensino tradicional em inúmeras vezes, assistimos à mera apresentação de conteúdos pelo professor, o aluno se comporta passivamente.

Tendo em conta a experiência realizada com a turma do Ensino Médio e os resultados obtidos, consideramos que a utilização das metodologias ativas aponta para várias potencialidades pedagógicas e contribuem para as melhorias dos processos de ensino e aprendizagem.

Logo, sentimos que um dos grandes desafios está ao nível da capacidade de promover este tipo de metodologias e dos professores as assumirem mais frequentemente em sua prática. Torna-se assim necessário, garantir processos de formação inicial ou continuada que possam ajudar aos professores a conhecer, selecionar, aplicar e avaliar os resultados educativos com o uso de metodologias ativas.

\section{Referências}

ALVES, L. Game Over: Jogos eletrônicos e violência. São Paulo: Editora Futura, 2005.

BARDIN, L. Análise de Conteúdo. 4a ed. Lisboa: Edições 70, 2008.

BERGMANN, J.; SAMS, A. Sala de aula invertida: uma metodologia ativa de aprendizagem. Rio de Janeiro: LTC, 2018.

BONWELL, C.; EISON, J. Active learning: Creating excitement in the classroom. Washington: The George Washington University, 1991. 
BRAGA, J. DE C. F. Ensino e aprendizagem de línguas via redes de participação. In: BRAGA, J. DE C. F. (Ed.). Integrando tecnologia no ensino de inglês nos anos finais do ensino fundamental. São Paulo: Edições SM, 2012. p. 8-21.

CAETANO, L. M. D. Tecnologia e Educação: quais os desafios? Educação | Santa Maria, v. 40, n. 2, p. 295-310, 2015.

CAETANO, L. M. D. Contribuições da tecnologia na pesquisa educacional. In: LENDL, A.; SAMPAIO, M. L.; OLIVEIRA, M. N. (Eds.). Pesquisas e ensino da leitura, literatura e língua portuguesa. Curitiba: Editora CRV, 2017. p. $121-136$.

CARR, N. Os superficiais. Lisboa: Gradiva, 2012.

EISON, J. Using Active Learning Instructional Strategies to Create Excitement and Enhance Learning. Tampa: [s.n.]. Disponível em: <https://www.cte.cornell.edu/documents/presentations/Active Learning Creating Excitement in the Classroom - Handout.pdf>.

FELDER, R.; BRENT, R. Active Learning: an Introduction. ASQ Higher Education Brief, v. 2, n. 4, p. 1-5, 2009.

GIBBS, G. Análise de dados qualitativos. Porto Alegre: Artmed, 2009.

KENSKI, V. M. Tecnologias e ensino presencial e a distância. 9a ed. Campinas. SP: Papirus, 2015.

KOSTER, R. A theory of fun for game design. Scottsdale, Arizona: ParaglyphPress, 2005.

LEITE, B. Aprendizagem Tecnológica Ativa. Revista Internacional de educação Superior, v. 4, n. 1, p. 1-30, 2018.

LIMA, B. S.; SANTOS, C. A. M. Peer-instruction Usando Ferramentas On-line. Revista de Graduação da USP, v. 1 , n. 1 , p. 83-90, 2016.

MAZUR, E. Peer Instruction: revolução da aprendizagem ativa. [s.I.] Penso, 2015.

MINAYO, M. C. DE S. Pesquisa Social: teoria, método e criatividade. 21a ed. Petrópolis: Editora Vozes, 2002.

MORAN, J. Educação Híbrida: um conceito chave para a educação, hoje. In: BACICH, L.; NETO, A. T.; TREVISANI, F. DE M. (Eds.). Ensino Híbrido: Personalização e tecnologia na educação. Porto Alegre: Penso, 2015. p. 27-45.

MORAN, J. Metodologia ativas para uma aprendizagem mais profunda. In: BACICH, L.; MORAN, J. (Eds.). Metodologias ativas para uma educação inovadora: uma abordagem teórico-prática. Porto Alegre: Penso, 2018. p. $1-25$.

OBLINGER, D.; OBLINGER, J. Educating the Net Generation. Brockport Bookshelf: New York, 2005.

OLIVEIRA, M. M. Como fazer pesquisa qualitativa. 7a ed. Petrópolis: Vozes, 2016.

PRENSKY, M. Nativos Digitais, Imigrantes Digitais. On the Horizon, v. 9, n. 5, p. 01-06, 2001.

PRENSKY, M. Teaching Digital Natives. Thousand Oaks: Corwin, 2010.

PRINCE, M. Does active learning work? A review of the research. Journal of Engineering Education, v. 93, n. 3, p. 223-232, 2004.

RHEINGOLD, H. Smart mobs: The next social revolution. Cambridge: Perseus Publishing, 2003.

RODRIGUES, E. F. Tecnologia, inovação e ensino de história: o ensino híbrido e suas possibilidades. Rio de Janeiro, Universidade Federal Fluminense, 2016.

RODRIGUES, E. P. Sala de aula invertida integrada à aprendizagem por pares: metodologias ativas comparadas à classe tradicional no ensino de História. São Paulo: Pontifícia Universidade Católica de São Paulo, 2019.

SAHAGOFF, A. P. Pesquisa Narrativa: uma metodologia para compreender a experiência humana. Sustentabilidade, Ciência e Ética, v. XI SEPesq, p. 2-7, 2015.

SANTOS, L. F.; TEZANI, T. C. R. Aprendizagem colaborativa no ensino de História: a sala de aula invertida como metodologia ativa. Renote, v. 16, n. 2, p. 101-111, 2018.

SANTOS, H.; VOLTER, B.; WELLER, W. Teorias e métodos. Civitas, v. 14, n. 2, p. 199-203, 2014.

VALENTE, A. Blended learning e as mudanças no ensino superior: a proposta da sala de aula invertida Blended Learning and Changes in Higher Education : the inverted classroom proposal. Educar em Revista, n. 4, p. 79-97, 2014.

VEEN, W.; VRAKKING, B. Homo zappiens: educando na era digital. Porto Alegre: Armed, 2009. 
VIEIRA, J. M.; FERRONATO, C. Linguagem e a crise dos saberes: micronarrativas na pós-modernidade. Revista Tempos e Espaços em Educação, v. 10, n. 23, p. 175-186, 2017.

VIVO, F. T. Juventude conectada 2. São Paulo: Fundação Telefônica Vivo, 2016.

YIN, R. K. Estudo de caso: planejamento e métodos. 2a ed. Porto Alegre: Bookman, 2001.

Recebido em julho de 2020.

Aprovado para publicação em abril de 2020.

\section{Adriana Moreira da Rocha Veiga}

Centro de Educação - Universidade Federal de Santa Maria - UFSM, Brasil, adrianaufsm@gmail.com

Luís Miguel Dias Caetano

Instituto de Ciências Sociais Aplicadas - Universidade da Integração Internacional da Lusofonia Afro-Brasileira - UNILAB, Brasil, migueldias@unilab.edu.br

\section{Márcia Mychelle Nogueira do Nascimento}

Programa de Pós-Graduação em Educação - Universidade Federal de Santa Maria - UFSM, Brasil, marciamychelle1@gmail.com 